\title{
The morphosyntax of number in Estonian numeral-noun constructions
}

\author{
Mark Norris*
}

\begin{abstract}
The interaction of numerals and number-marking has generated much research in both morphosyntax and semantics in those domains. In this paper, I propose an analysis of number-marking in the numeral-noun constructions of Estonian. They are noteworthy for the existence of two morphosyntactic frames. In one, both the numeral and noun are singular, and the noun bears partitive case. In the other, both the numeral and noun are plural, and there is no assignment of partitive case. I propose an analysis whereby the head assigning partitive case is of the same syntactic category as the head introducing plurality: Borer's (2005) Div ${ }^{0}$. Previous accounts do not capture the generalization that the numeral always matches the noun's numbermarking. I propose it is another instance of the language's already robust system of nominal concord.
\end{abstract}

Keywords. number; plural-marking; case; numerals; agreement; Estonian

1. Introduction. A major area of study within nominal morphosyntax is the combination of (cardinal) numerals and nouns (hereafter numeral-noun constructions, or NNCs), and more specifically, the number-marking of nouns in such constructions. ${ }^{1}$ Compare the English and Hungarian examples in (1)-(2).

(1) English:
a. * two dog
b. two dog-s

(2) Hungarian:
a. három gyerek three child
b. * három gyerek-ek three child-PL

In English, two can combine with plural dogs but not singular dog. The pattern is reversed in Hungarian, where numerals combine only with singular nouns. The existence of both patterns has influenced both syntactic and semantic analyses of numerals, especially where they intersect with analyses of the morphology or semantics of plural-marking.

In this paper, I explore NNCs in Estonian (Finno-Ugric; Estonia), where numerals can combine with both singular and plural nouns, as shown in (3)-(4). ${ }^{2}$

\footnotetext{
* For assistance with this project, I thank Sandy Chung, Jorge Hankamer, Ruth Kramer, Jim McCloskey, Sarah Ouwayda, and audiences at the 2017 Syntax Of Uralic Languages workshop in Budapest and the 2018 meeting of the LSA in Salt Lake City. Thanks as well to the following speakers of Estonian sharing their time and discussing their language with me: Katrin Jänese, Mervi Kalmus, Leelo Kask, Kärt Lazić, Maarja Lutsar, Maire Moisto, and Siim Põldre. I am responsible for any errors herein. Author: Mark Norris, University of Oklahoma (mark-norris@ ou.edu) ${ }^{1}$ Generally speaking, when I use the term numeral here, I mean numerals other than one.

${ }^{2}$ Glossing abbreviations are as follows: 2 second person, 3 third person, ADE adessive case, ALL allative case, DEM demonstrative, ELA elative case, GEN genitive case, IMP imperative, INE inessive case, NOM nominative case, PAR partitive case, PL plural number, PRS present tense, TRL translative, SG singular number
} 
(3)

Singular NNCs ([SG]-NNCs):
a. kaks inimes- $t$
2.SG.NOM person-SG.PAR
'two people'
$\begin{array}{lll}\text { b. } & \text { neli } & \text { särki } \\ & \text { 4.SG.NOM } & \text { shirt.SG.PAR }\end{array}$
'four shirts'

\section{(4) Plural NNCs ([PL]-NNCs):}
a. kahe-d kangastelje-d
2-PL.NOM loom-PL.NOM
'two looms'
b. nelja-d kääri-d
4-PL.NOM scissors-PL.NOM
'four pairs of scissors'

In (3), we see numerals combining with singular nouns, and in (4), we see numerals combining with plural nouns. Importantly, the numeral matches the number-marking on the noun. Thus, in (4), both the numeral and the noun are marked for plural, and in (3) they are unmarked (and thus effectively singular). A second important observation to make is that the noun is marked with partitive case in [SG]-NNCs, but there is no special case-marking in [PL]-NNCs. ${ }^{3}$

There are thus two primary questions to address. First, how do we capture the fact that partitive case-marking is used only in [SG]-NNCs? That is, how can we account for the apparent complementarity of plural-marking and partitive case in NNCs? Second, how do we capture the fact that the numeral always matches the noun's number value? In this paper, I propose that the numeral's number value is just another instance of Estonian's robust system of nominal concord (Norris 2014). In answer to the first question, I propose a Borer (2005)-style analysis whereby a Div $^{0}$ head can either (i) introduce plurality or (ii) assign partitive case to its complement, but not both.

The paper proceeds as follows. In section 2, I provide more detail on the kinds of interpretations permissible for [PL]-NNCs. I propose my analysis in sections 3 and 4, answering the above questions in turn. In section 5, I discuss some previous work on NNCs in Finnish, arguing that the approaches all fail to capture the generalization that the numeral and noun always match in number-marking. In section 6 , I consider some data showing that there must be an additional head introducing plurality in [SG]-NNCs. Section 7 concludes.

2. Interpretations for [PL]-NNCs. Though both [SG]-NNCs and [PL]-NNCs exist in Estonian, they are not semantically interchangeable. In [SG]-NNCs, numerals always count atomic individuals. In [PL]-NNCs, numerals count sets of different sizes, dependent both on the noun being counted and on the context (i.e, the interpretation intended). ${ }^{4}$ The nouns I gave in (4)_kangasteljed 'loom' and käärid 'scissors' - are so-called pluralia tantum nouns: nouns which must always be plural. Pluralia tantum nouns are some the classic examples of nouns which are counted using [PL]-NNCs, but the range of nouns that can be used is broader than that.

To get a sense of the range of interpretations available to counted groups in [PL]-NNCs, I conducted a corpus search. I pulled a total of 418 [PL]-NNC examples from three corpora: BAL-

\footnotetext{
${ }^{3}$ The noun only bears partitive case in nominative and accusative contexts. In other contexts, the numeral and noun bear the same case. I ignore those contexts here, but see Norris (To Appear) for discussion and a possible analysis. ${ }^{4}$ I believe it would be too terse to say that numerals count groups larger than one in [PL]-NNCs due to the fact that pluralia tantum nouns must be counted with [PL]-NNCs. There is obvious morphological appeal in assuming that pluralia tantum nouns denote groups given that they bear plural-marking, but I do not find it intuitive, and thus I do not make such an assumption here. Testing whether predicates requiring semantically plural arguments (e.g., gather and the like) can be used with pluralia tantum nouns would provide an argument for or against treating them as group-denoting, but I do not resolve this issue here.
} 
ANCED, a balanced literary corpus containing equal parts journalism, fiction, and scientific articles; ETTENTEN, a corpus of examples pulled from the internet; and PARLIAMENT, a corpus of stenographic records of parliamentary speech. I divided the results into four groups based on interpretation: pluralia tantum/plerumque, natural groups, contextual groups, and kinds.

2.1. [PL]-NNCS: PLURALIA TANTUM/PLERUMQUE. As mentioned at the outset, pluralia tantum nouns are counted using [PL]-NNCs. However, as noted by Acquaviva (2008), it is difficult to delimit the bounds of pluralia tantum with precision. In the largest online Estonian-language dictionary of Estonian (Eesti keele seletav sõnaraamat), some nouns (e.g., käärid 'scissors') are marked $p l$, indicating that they must be plural, i.e., they are pluralia tantum nouns. ${ }^{5}$ As we saw in (4a-b), these nouns are counted using [PL]-NNCs.

In addition, there are nouns which are marked "normally plural" ( $\mathrm{hrl} . \mathrm{pl} .=$ harilikult pluural) as well as nouns that are marked "also plural" ( $k a \mathrm{pl} .=\mathrm{ka}$ pluural). In other words, there are nouns which are not strictly speaking pluralia tantum but may nevertheless be plural without a clear interpretive difference. These nouns can also be counted using [PL]-NNCs, as shown in (5)-(6) below.

(5) kolme-d viimase-d valimise-d three-PL last-PL election-PL 'three last/previous elections'

(ETTENTEN)

(6) kahe-d talgu-d

two-PL bee-PL

'two bees (communal work sessions)'

In the aforementioned dictionary, the noun valimised 'election(s)' in (5) is marked "normally plural" and the noun talgud 'bee' in (6) is marked "also plural". I call these nouns pluralia plerumque 6 and I group them with pluralia tantum nouns given that the borders delineating which nouns are pluralia tantum and which are not pluralia tantum are not clear, as Acquaviva (2008) convincingly shows. As can be seen from these examples, these kinds of nouns are also counted using [PL]NNCs.

2.2. [PL]-NNCS: NATURAL GROUPS. The corpus also contains numerous examples of nouns which denote objects that have very salient possible groups based on real-world knowledge. This class of nouns has no inherent connection to plural in the way that the previous group does, but they can also be counted with [PL]-NNCs. Examples showing kindad 'gloves' and jäljed 'legs/tracks' are given below.

(7) a. kahe-d kinda-d

two-PL glove-PL

'two pairs of gloves'

b. kahe-d erineva-d karujälje-d

two-PL different-PL bear.track-PL

'two different sets of bear tracks'

(ETTENTEN)

However, unlike pluralia tantum nouns, which must be counted with [PL]-NNCs (so far as I know),

${ }^{5}$ This journal can be accessed at http://www.keeleveeb.ee/.

${ }^{6}$ Pluralia plerumque is intended to mean 'plural most of the time'. Thanks to Erik Zyman, p.c., for creating the

Latin version of this idea. 
nouns like these can also be counted using [SG]-NNCs. However, the choice between [SG]-NNCs and [PL]-NNCs is not free- there is a clear interpretive difference. Whereas [PL]-NNCs count groups of nouns, e.g., pairs in (7a) and sets in (7b), [SG]-NNCs count individual units, as in (8).
a. kaks kinnas-t
two.SG glove-SG.PAR
'two (individual) gloves'
b. kaks kinga
two.SG shoe-SG.PAR
'two (individual) shoes'

The analysis I propose in section 3 captures this by saying that numerals essentially count whatever they merge with. If they merge with something denoting a plurality (as in a [PL]-NNC), then they count instances of that plurality (as opposed to, for example, fixing the cardinality of that existing set). ${ }^{7}$

2.3. [PL]-NNCS: CONTEXTUAL GROUPS. In fact, a noun need not even have an obvious natural grouping to be counted using [PL]-NNCs. Brattico (2011) and Hurford (2003) make much the same observation for Finnish. If the context makes a salient grouping available, [PL]-NNCs then count those groups. Two corpus examples are presented below with context (translated to English).

(9) For that reason it was very cool that did so well in this group: reaching the seminfinals were three English-speaking teams, ...
a. kolme-d eestlase-d, $\quad \ldots$ three-PL Estonian-PL
'three sets of Estonians; three Estonian teams'
b. ühe-d sakslase-d Bremeni-st ja ühe-d leeduka-d. one-PL German-PL Bremen-ELA and one-PL Lithuanian-PL 'one German team from Bremen and one Lithuanian team'

(ETTENTEN)

(10) "And do you have eggs?"

"Hmmm, we should-" S/he went in the kitchen to check and came back to the dining room — "We have three eggs left —"

I said, "Very good. Lay a fourth one and...
a. teh-ke mei-le kahe-d härjasilma-d.
make-IMP.2PL us-ALL two-PL fried.egg-PL
'Make us two groups (pairs) of fried eggs.'

(BALANCED)

The example in (9) discusses the results of a debate competition, where participants com-

\footnotetext{
7 There appears to be a systematic exception to this property from decimal numerals, e.g., kümme 'ten', sada 'hundred', and tuhat 'thousand'. In the corpus examples I have found, something like saja-d inimese-d 'hundred-PL person-PL' really does seem to mean something akin to the English hundreds of people rather than 'exactly one hundred sets of people'. To be sure, those two interpretations could be difficult to tease apart (both would be used to refer to groups of people numbering roughly 200 or more), but the second interpretation seems on the face of it so peculiar that it would surely be surprising to find that that is what it actually means. Unfortunately, I have nothing concrete to say about this difference at present, as I have yet to conduct systematic fieldwork on the constructions.
} 
peted in groups. Thus, while the noun eestlane 'Estonian' does not have an obvious natural grouping, in a debate competition where there are teams from various regions, such groups become possible, and [PL]-NNCs count those groups. In (10), fried eggs are being counted, and these do not obviously have a natural grouping into pairs. However, the context makes clear that there are (or should be) four total eggs, and thus, kahe-d härjasilma-d 'two-PL eggs-PL' takes on its meaning of 'two pairs of eggs'.

2.4. [PL]-NNCS: KINDS/SORTS. Finally, there are examples of [PL]-NNCs where what are counted are not discrete individuals (or groups of individuals), but kinds or sorts. This is exemplified in the examples below.

(11) Kui mei-l on kahe-d kraadi-d, teaduskraadi-d ja kutsekraadi-d, If we-ADE be.PRS.3 two-PL degree-PL, scientific.degree-PL and professional.degree-PL $\cdots$

'If we have two degrees, scientific degrees and professional degrees, ...

and if they have the same name, then that means - the scientific degree is for example 'economic doctor' and the professional degree is 'doctor of economics' - then we don't really have two degrees, then it's still just one degree?'

(PARLIAMENT)

(12) On

olema-s kolme-d tähe-d: taeva-, kirja- ja raha-.

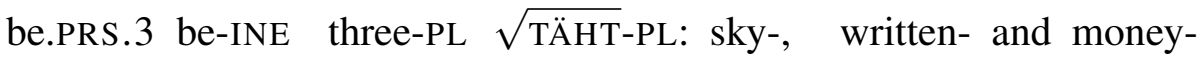

'Three are three kinds of täht: sky- (stars), written- (letters), and money- (bills) (ETTENTEN)

In (11), the [PL]-NNC kahed kraadid 'two-PL degree-PL' refers to two types of degrees under discussion (as opposed to two sets of contextually salient degrees). The example in (12) is particularly interesting, because it references the polysemy of the root täht in Estonian, which can either mean 'star', 'letter/grapheme', or 'bill/note'.

In fact, it is not particularly surprising that [PL]-NNCs can be used to count kinds as well as groups of discrete individuals. There is a well-known affinity between plurality and kind denotation (see, for example, Chierchia (1998)), and plurals in Estonian can denote kinds outside of [PL]-NNCs as well. An example of this is provided below in (13).
Ninasarviku-d on
hävimisohus.
rhinoceros-PL.NOM be.PRS.3 endangered
'Rhinoceroses are endangered.' 8

Thus, plural-marking in Estonian (as in many other languages) must independently be compatible with kind interpretations. The fact that they emerge in NNCs is thus expected.

2.5. [PL]-NNCS: SUMMING UP. Because [PL]-NNCs are used with pluralia tantum nouns (among other things), it is tempting to equate their use with what Acquaviva (2008) calls lexical plurality, and I did exactly that in earlier versions of this work. However, this requires a sort of generalized lexical plurality, because it seems that any noun can be used in [PL]-NNCs given the proper context. Informally, [PL]-NNCs count whatever (salient) groups are made available by the noun's interpretation and the context, but it is not clear to me that those interpretations necessarily differ from ordinary plural interpretations. In addition, the plurals in [PL]-NNCs are also morphologi-

\footnotetext{
${ }^{8}$ http://tallinnzoo.ee/kas-tead-et-teravmokk-ninasarvik-uks-ohustatumaid-liike-maailmas/, accessed 02/21/2018.
} 
cally regular. Thus, there does not appear to be anything lexically exceptional about these plurals, making the label lexical plurality seem inaccurate.

This reminds me of the patterns Deal (2017) discusses in her analysis of a different domain of nominal semantics in Nez Perce: mass and count. Although Nez Perce has a rather fluid boundary between mass and count terms, Deal ultimately argues that Nez Perce does encode a difference between mass and count. As part of her analysis, Deal proposes a silent partitioning head $\alpha^{0}$, which divides mass denotations into countable units. She demonstrates that the available partitions (i.e., interpretations) defined by this head are influenced by context and real-world knowledge connected to the interpretation of the noun in question. The observations from the present article remind me of this, because in [PL]-NNCs, the numerals count whatever groups are available for the particular noun, again determined by context (e.g., debate teams) or real-world knowledge (e.g., the knowledge that gloves and mittens come in pairs).

One important distinction between Deal's proposal and the facts considered here is that Deal focuses on $\alpha^{0}$ as introducing a variable over atomization functions, and [PL]-NNCs do not obviously count atoms. Still, the connection seems like a promising direction for developing a formal semantic account for NNCs in Estonian. I leave the formalization of such an account to future work.

3. Analysis, part 1: Div $^{0}$ as [PL] or [PAR]. Recall the empirical generalizations relevant for NNCs in Estonian. First, the number-marking of the numeral always matches the number-marking of the noun. In [PL]-NNCs, both the numeral and noun are plural, and in [SG]-NNCs, both are singular. Second, in [SG]-NNCs (but not in [PL]-NNCs), the noun is marked with partitive case (in nominative/accusative contexts; see footnote 3 ).

To account for the complementarity of plural-marking and partitive case, I propose that both are connected to the same syntactic position. Specifically, I propose that partitive case-marking is the reflex of a syntactic classifier- "syntactic" because it is not lexicalized as in traditional classifier languages. Following Borer (2005), this classifier realizes the same syntactic node as the $[\mathrm{PL}]$ feature; this captures the complementarity of plural-marking and partitive case-marking. Following Borer (2005), Mathieu (2014), I refer to this head as Div ${ }^{0}$.

Div $^{0}$ merges directly with NP, and numerals are merged after DivP. The syntactic position of cardinal numerals is hotly debated; strictly speaking, their syntactic position does not matter for the analysis I propose, so I assume they are specifiers of a CardP projection for concreteness. This is also closely in line with Borer's (2005) structures. With these proposals, the structures for both kinds of NNC are shown below.

(14) a. kaks kinnas-t

two.SG glove-SG.PAR

'two (individual) gloves' 
b.

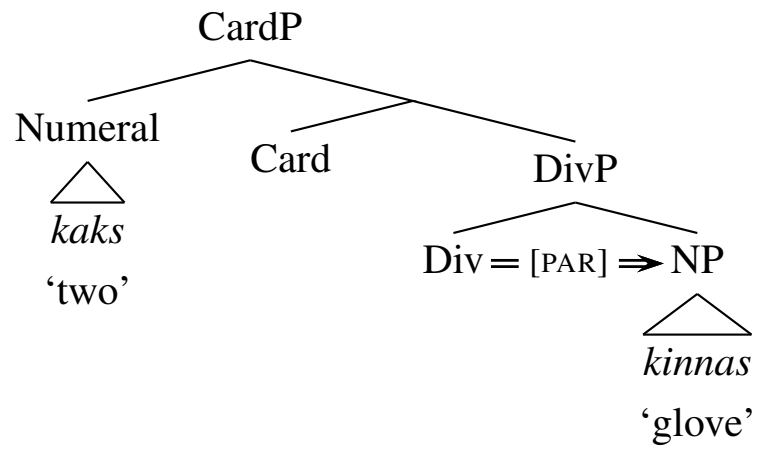

(15)

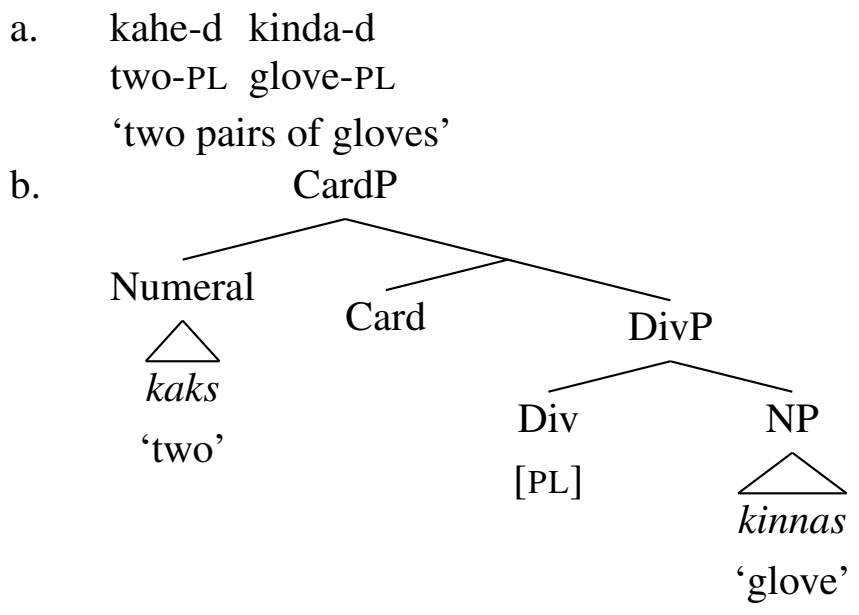

One benefit of the structures above is that both [PL]-NNCs and [SG]-NNCs can be given the same syntactic structure. This contrasts with Danon (2012), who suggests that Finnish numerals are heads in [SG]-NNCs but specifiers in [PL]-NNCs. This is largely because under his proposal, numerals as heads always assign case and numerals as specifiers always show concord with the noun but do not assign case (Danon 2012:1282-1283). However, the account does not clearly explain why numerals cannot be heads when the noun is plural (or specifiers when the noun is singular).

Danon suggests that the lack of partitive case in [PL]-NNCs could be because [PL] and [PAR] are in competition, though he does not formalize this suggestion (Danon 2012:1304-1305). Note that this is not broadly true, as [PL] and [PAR] are realized together quite frequently in the language. For example, they are realized together in the language's pseudopartitive construction, exemplified below.

$$
\begin{aligned}
& \text { a. parv pääsukesi } \\
& \text { flock swallow.PL.PAR } \\
& \text { 'a/the flock of swallows' }
\end{aligned}
$$

b. kott kartule-id

bag potato-PL.PAR

' $a$ /the bag of potatoes'

In these examples, the second nouns_pääsukesi 'swallows' and kartuleid 'potatoes' - bear partitive case and plural number, and so there is nothing inherently incompatible about these values. In my analysis, the apparent incompatibility arises because the head assigning partitive case in 
NNCs is of the same lexical category as the head introducing plural number. Thus, they cannot occur together in this particular construction, but in other constructions (like the pseudopartitive), it is reasonable that a different head could be responsible for assigning partitive case. See Norris (To Appear) for a possible analysis along these lines.

4. Analysis, Part 2: number-marking due to concord. As we have seen, the numeral's numbermarking always matches the number-marking on the noun. When the noun is singular, so is the numeral, and when the noun is plural, so is the numeral. I propose that this is because the numeral obtains its number value via nominal concord, which is independently necessary for Estonian. Nearly every element in the Estonian nominal phrase shows concord for case and number (the major exception is adnominal possessors), as shown in the examples below.
a. selle-ks vahepealse-ks perioodi-ks
this-TRL in.between-TRL period-TRL
'for this interim period'
b. kõigi-s nei-s raske-te-s küsimus-te-s
all.PL-INE this.PL-INE difficult-PL-INE questions-PL-INE
'in all these difficult questions'

For example, in (17a), every element inflects for translative case (and singular number, though this is not reflected morphologically). The same is true in (17b) for plural number and inessive case. Concord is a robust part of nominal morphosyntax in Estonian. Regarding numerals specifically, it is already clear that numerals show case concord based on examples like the following.
a. kolme poisi
three.GEN boy.GEN
'(of) three boys'
b. viie-1 päeva-1
five-ADE day-ADE
'five days (adessive case)'

(BALANCED)

(ETTENTEN)

In (18a), the numeral and noun both bear genitive case, and in (18b), both bear adessive case.

Thus, the claim that numerals show concord for number is well-motivated. ${ }^{9}$

As for the formalization of concord, most existing analyses of nominal concord could account for it in this case (see Norris (2017) for a recent review of approaches). I do not believe that number concord on Estonian numerals provides evidence in support of any particular proposal, and so I do not adopt a specific one here. Instead, I present an agnostic schematization for concord involving the [PL] feature in (19). ${ }^{10}$

\footnotetext{
${ }^{9}$ The careful reader may be wondering what happened to the partitive case in examples such as these. I do not discuss this issue here, but see Norris (To Appear) for a possible analysis. The assumptions about numerals are slightly different there, but I think the account proposed here could be incorporated with the analysis of case-marking proposed there; it would just require that the trigger for partitive case be changed from "complement of $\mathrm{N}^{0}$ " to some other property that could include both numerals and measure nouns in pseudopartitives.

${ }^{10} \mathrm{As}$ an aside on formalization, I must note that this analysis makes use of privative number features, such that singular number is formally treated as absence of [PL] rather than an independent singular feature [SG]. This is because [SG] is not actually introduced by a head- Div ${ }^{0}$ is either the case-assigning "classifier" or the plural-marking head. Of course, we could stipulate that the classifier Div ${ }^{0}$ is also specified as [SG], but it seems to me that that stipulation less elegantly captures the complementarity of plural-marking and case-marking in NNCs. I leave this possibility open here; perhaps additional evidence can be furnished in favor of one approach.
} 
(19)

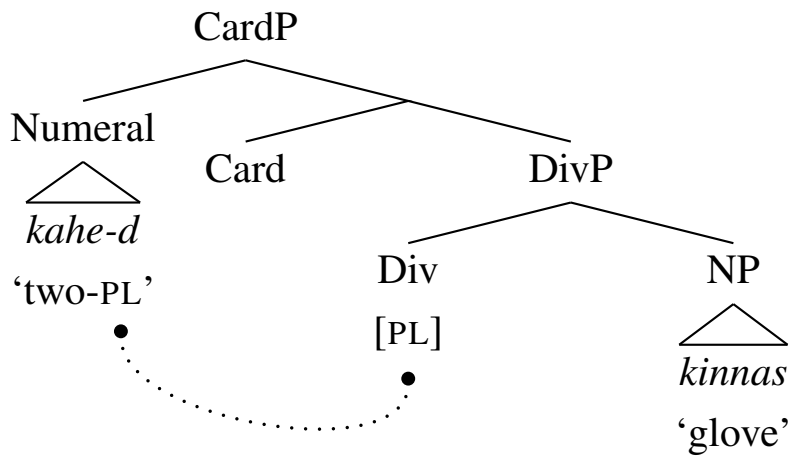

The key insight is that the numeral's number value is never pre-specified-it is merged with a structure and acquires whatever number-value is associated with that structure. In this respect, my proposal differs from most previous approaches I am aware of. Let us turn to a discussion of such approaches now.

5. Previous work (on Finnish): lexically-stipulated [SG]. Though the Estonian pattern has not been analyzed, a number of authors have discussed Finnish, which exhibits the same phenomena as Estonian in its numeral-noun constructions. In section 3, I discussed Danon's (2012) brief analysis of Finnish. In this section, I discuss two additional strands of research. They share the assumption that numerals are (at least in some instances) pre-specified for their number values, which misses the generalization the the numeral's number value always matches the value of the noun.

5.1. BRATtico: Q-NUMERALS AND A-NUMERALS. In a series of papers, Brattico (2010, 2011, 2012) analyzes NNCs in Finnish, focusing in large part on the alternation between case-assignment (i.e., the partitive case seen here) and case concord (when the numeral and noun match in case). He proposes that the Finnish lexicon contains two entries for each numeral: [PL]-NNCs contain A-numerals, and [SG]-NNCs contain Q-numerals (Brattico 2012:37). These numerals are distinguished in the lexicon: Q-numerals are endowed with an uninterpretable [SG] feature.

While the distinction between A-numerals and Q-numerals may be useful as a way to speak descriptively about their morphosyntactic behavior, having two separate forms of numerals in the lexicon is an unnecessary stipulation. First, it misses the generalization that the plural and singular numerals are clearly built from the same root, following ordinary morphological templates in the language. Listing the numerals separately in the lexicon would have more support if some of the numerals had unique or irregular forms. Second, the fact that the numeral is singular whenever the noun is singular cannot be attributed to the independently necessary system of nominal concord, because the numeral's number value is lexically stipulated in that case. Brattico does not analyze [PL]-NNCs, so we cannot be sure how they would be incorporated into his account. They would presumably be treated as A-numerals, but in that case, it would not be obvious how we could exclude them from appearing when the noun is singular.

5.2. LANDAU: NUMERALS HAVE INHERENT NUMBER FEATURES. Landau (2016:1005-1006) briefly considers NNCs in Finnish, focusing on the fact that higher modifiers (like demonstratives) must be plural, even with [SG]-NNCs. The analysis of Finnish is intended to fit in with his general analysis, which is that NumP (merging with NP) is the locus of the semantically-based plural value (INDEXIPLURAL). He ultimately proposes that this $\mathrm{Num}^{0}$ head must merge before the numeral for reasons of semantic composition, and this results in a structure like the follow- 
ing. ${ }^{11}$

(20)
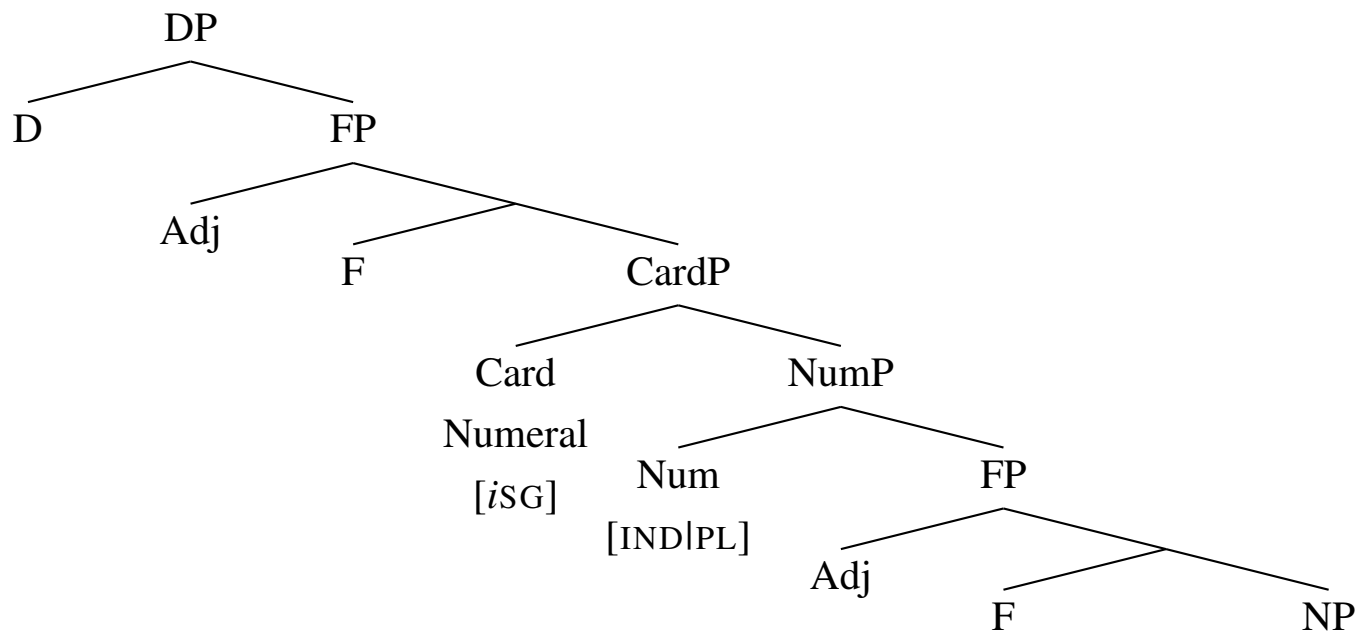

However, the mechanism that he proposes for concord predicts that the numeral would be plural in this instance, matching the number value accessible on Num ${ }^{0}$. However, Landau suggests that the singular value on numerals is not the result of concord but is instead an inherent, interpretable feature (Landau 2016:fn24), represented in (20) as [iSG]. ${ }^{12}$ This is reminiscent of Brattico's proposals with the small difference that, for Brattico, the number feature is uninterpretable. In support of his suggestion, Landau notes the existence of [PL]-NNCs, saying they have what he calls a "layered plurality." Finishing the chain of reasoning, the idea is that because plural-marking on the numeral coincides with a different interpretation, the numeral's number value must be interpretable. Note that it need not be interpretable on the numeral itself; the numeral could just reflect some other difference in the structure. However, Landau does not further specify what he means by layered plurality, and he does not go into detail about how the numeral's proposed inherent number value interacts with the system that he develops (e.g., why do higher modifiers pick up the plural feature, which appears to be lower in the structure than the singular feature on the numeral?). Thus, it suffers from many of the same issues as Brattico's proposal

5.3. PREVIOUS WORK: SUMMARY. In previous work, numerals are pre-specified with their own number values (at least some of the time), and thus, the fact that number-marking on the numeral always matches number-marking on the noun is not captured by the analyses. Treating numbermarking on the numeral as just another instance of the language's robust nominal concord predicts that the numeral's number-marking should match the noun.

\footnotetext{
${ }^{11}$ Landau's (2016) structures are simplified, and so what I present here is modified somewhat. I use 'FP' for head/phrase labels that Landau leaves blank. In addition, I treat Card ${ }^{0}$ here as a head in the nominal spine, but as far as I can tell, Landau does not actually take a stance on this for Finnish. The other option would be an additional functional projection with CardP in the specifier position.

${ }^{12}$ It is worth pointing out that, in Landau's proposed theory, every inherent number feature is typed (it is either an INDEX feature or a CONCORD feature), but he does not specify what type of feature the numeral would bear in this case. Treating it as a CONCORD feature makes the most sense to me (given that the same extended projection could not have both a singular INDEX and a plural INDEX), but this leads to a situation where a CONCORD feature is merged after an INDEX feature of the same type, which runs counter to the way these sorts of mismatches typically play out. I do not resolve this issue here, but see Landau (2016), Wechsler \& Zlatić (2003) for more discussion.
} 
6. The switch to [PL] in [SG]-NNCs. All of the examples discussed so far only contain numerals and the constituents they merge with. Interestingly, higher modifiers merged with [SG]-NNCs (e.g., demonstratives, adjectives merged after the numeral) must be plural. This is clearest from adjectives, as visible in the minimal pair below.
a. nee-d
nee-d viis
DEM-PL.NOM 5.SG.NOM bea
'these five beautiful houses'
ilusa-t
maja

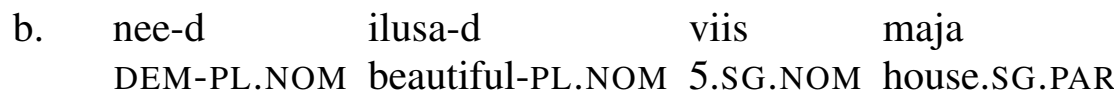
'these beautiful five houses'

(Erelt et al., 1993)

In (21a), the adjective ilusat 'beautiful-SG.PAR' is on the right of the numeral, and it is singular (and partitive). In (21b), the same adjective is on the left of the numeral, and it is plural (and nominative) ilusad.

Landau (2016) investigated similar facts, proposing (for Finnish) that [SG]-NNCs have a [PL] feature introduced on Num ${ }^{0}$, crucially merged before the Numeral (in $\mathrm{Card}^{0}$ ). Given those proposals, Landau's system predicts plural-marking on the numeral - he proposes that numerals are lexically specified as [SG]. The proposal is made only in brief, and so some questions remain unanswered (as I discussed in section 5).

I would like to suggest instead that a second [PL] feature is merged after the numeral, following Mathieu (2014) among others. In Mathieu's terms, this plural would be a counting plural.

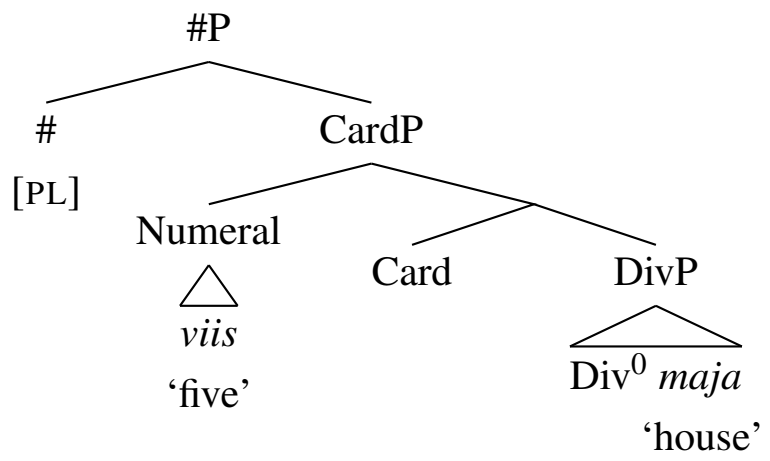

Under most analyses of nominal concord, we expect demonstratives and high adjectives merging after \# to be marked plural. See Norris (2014) for an analysis that is broadly similar (though the assumptions about locations of number features are slightly different). Of course, this raises more questions about number-marking and numerals, and I will not answer them here. This is clearly one of the next steps this project should take.

7. Conclusions \& future directions. In this paper, I proposed that number-marking on numerals in Estonian is another instance of the language's robust system of nominal concord. More concretely, I proposed that numerals merge with a DivP projection headed by $\mathrm{Div}^{0}$ that is either plural-marking or a phonologically null classifier that reveals itself through partitive case assignment to its NP complement. The numeral itself then acquires its number value (singular or plural) through concord, thus deriving the fact that plural numerals are only used with plural nouns and singular with singular.

In this analysis, what makes Estonian special is not the existence of two types of numerals 
or stipulation of a [SG] feature on singular numerals, but the presence of both number-marking and a (purely syntactic) classifier in the language. There has long been a debate about the putative complementarity of classifiers and number-marking. While it seems to be the case that there are languages where both classifiers and plural-marking exist, the proposed complementarity can still shed light on morphosyntactic behavior, including in languages without lexicalized classifiers (like Estonian).

The clearest next step is to pair this syntactic analysis with a careful semantic analysis of the pieces involved. Two pertinent questions present themselves. First, what is the semantics of numerals such that they can combine with both classifier structures and pluralized non-classifier structures? Second, what does the switch to plural in [SG]-NNCs (discussed in Section 6) contribute to the semantic interpretation, if anything?

There are many known disconnects between morphological plural-marking and semantic plural interpretation (to the extent that it is possible to delineate precisely what plural interpretation means). Concord straightforwardly falls into that class, displaying a sort of many-to-one connection between exponence and interpretation of plurality. There has also been much debate about what to make of number-marking with numerals, with some authors proposing that pluralmarking on nouns with numerals is not the same as plural-marking on nouns in the absence of numerals (e.g., Krifka (1989:85) suggesting that plural-marking with numerals is "purely syntactic;" see also Deal (2017) for a more formal version of this idea). Estonian shows that completely discounting number-marking in numeral-noun constructions is perhaps too strong a position. Furthermore, the phenomenon considered here suggests that, when considering how number and numerals combine in languages with concord, we should pay attention not just to number-marking on nouns, but also number-marking on numerals, to the extent that it is visible in the language under discussion.

\section{References}

Acquaviva, Paolo. 2008. Lexical plurals: A morphosemantic approach. Oxford University Press. Borer, Hagit. 2005. Structuring sense, volume I: In name only. Oxford: Oxford University Press. Brattico, Pauli. 2010. The two-part models and one-part models of nominal case: evidence from case distribution. Journal of Linguistics 45. 47-81.

Brattico, Pauli. 2011. Case assignment, case concord, and the quantificational case construction. Lingua 121. 1042-1066.

Brattico, Pauli. 2012. Case assignment and phi-agreement in Finnish. SKY Journal of Linguistics 25. 29-59.

Chierchia, Gennaro. 1998. Reference to kinds across language. Natural language semantics 6(4). 339-405.

Danon, Gabi. 2012. Two structures for numeral-noun constructions. Lingua 122. 1282-1307.

Deal, Amy Rose. 2017. Countability distinctions and semantic variation. Natural Language Semantics .

Hurford, J.R. 2003. The interaction between numerals and nouns. In Franz Plank (ed.), Noun phrase structure in the languages of Europe Empirical Approaches to Language Typology/Eurotyp, 561-620. Mouton de Gruyter.

Krifka, Manfred. 1989. Nominal reference, temporal constitution and quantification in event semantics. In R. Bartsch, J.F.A.K. van Benthem \& P. von Emde Boas (eds.), Semantics and contextual expression, 75-115. Dordrecht: Foris Publications. 
Landau, Idan. 2016. DP-internal semantic agreement: A configurational analysis. Natural Language \& Linguistic Theory 34(3). 975-1020.

Mathieu, Éric. 2014. Many a plural. In Ana Aguilar-Guevara, Bert Le Bruyn \& Joost Zwarts (eds.), Weak referentiality, 157-182. Amsterdam: Benjamins.

Nemvalts, Peep. 1996. Case Marking of Subject Phrases in Modern Standard Estonian. Stockholm: Almquist \& Wiksell International.

Norris, Mark. 2014. A theory of nominal concord: University of California, Santa Cruz dissertation.

Norris, Mark. 2017. Description and analyses of nominal concord (parts I-II). Language and Linguistics Compass 11.

Norris, Mark. To Appear. Unmarked case in Estonian nominals. Natural Language \& Linguistic Theory.

Wechsler, Stephen \& Larisa Zlatić. 2003. The Many Faces of Agreement. CSLI Publications. 